\title{
UM ENSAIO SOBRE AS VIRTUDES: DO BEM SUPREMO A PERSONIFICAÇÃO
}

\section{Thiago Stadler ${ }^{1}$}

RESUMO: A palavra Virtude apresentou várias conotações ao longo da História, todavia entendemos que seu conteúdo moral-filosófico originou-se com os filósofos gregos. Com Platão e Aristóteles começa as teorizações acerca da natureza das Virtudes, na tentativa de entender qual a finalidade de ser um homem virtuoso. A boa-aventurança, o equilíbrio e a felicidade são algumas das respostas encontradas por estes filósofos, contudo até mesmo o homem virtuoso estaria sujeito a sofrimentos e infortúnios. Esta idéia dificilmente seria aceita em outros períodos em que a virtuosidade deveria assumir o posto da perfeição. Mais do que entender a natureza das Virtudes, passamos a buscar um exemplo carnal para expressar a felicidade e o equilíbrio ditado pelos gregos. É esta nova concepção de Virtude que encontramos no Principado de Trajano (98 - 117 d.C), onde Plínio, o Jovem buscou construir uma imagem ideal através das Virtudes. Da moralidade virtuosa grega às virtudes políticas romanas, um passo decisivo para entendermos a idealização de um Soberano.

PALAVRAS-CHAVE: Virtudes Morais, Virtudes Políticas, Personificação; Principado de Trajano, Plínio, o Jovem.

ABSTRACT: The word Virtue presented several connotations throught the History, however we understand that its moral-philosophical content originated with the greek philosophers. With Platão and Aristotle begins the theorize about the nature/essence of the Virtues, in the attempt of understand which the purpose of be a virtuous man. The equilibrium and the happiness are some of the answers found by these philosophers, however even the virtuous man would be subject to sufferings and misfortunes. This idea hardly would be accepts in others periods in that the virtuosity should assume the position of the perfection. More than understand the nature of the Virtues, we pass it seek a human example for express the happiness and the equilibrium dictated by the greeks. It is this new conception of Virtue that find in the Principality of Trajan (98-117 d.C), where Pliny, the Youth sought to build an ideal image through the Virtues. Of the greek virtuous morality to the roman political virtues, a decisive pace understand the idealization of a sovereign.

${ }^{1}$ Graduando do curso de Licenciatura e Bacharelado em História da Universidade Federal do Paraná (UFPR). 
KEY-WORDS: Moral Virtues, Political Virtues, Human Example, Principality of Trajan, Pliny, the Youth.

"Disposição habitual para a prática do bem; boa qualidade moral; castidade; coragem". Estas são algumas das definições que encontramos em nossos dias para a palavra Virtude. Todas se remetem a ações legitimadoras do bem, contudo são definições que pairam sobre um terreno abstrato. Esta abstração passa a ser melhor entendida se voltarmos para a origem do vocábulo Virtude. Esta palavra deriva do latim Virtute, entretanto suas qualidades, seu conteúdo moral-filosófico abstrato são originariamente gregas ${ }^{2}$. Desta forma, é inevitável não nos remetermos a Sócrates, Platão (428-347 a.C) e Aristóteles (384-322 a.C) quando o assunto recai sobre as abstrações do conhecimento. Dessa maneira, buscaremos traçar alguns momentos que elucidem a questão sobre as Virtudes, começando pelos filósofos gregos e seguindo na direção dos novos usos que esta palavra ganhou em períodos posteriores.

Uma questão inicial já nos aparece neste primeiro momento: se a palavra Virtude derivou-se do latim Virtute, como se deu o uso desta no mundo grego? A resposta é encontrada em algumas obras ${ }^{3}$ de Platão - Carmides, Mênon, A República - onde o filósofo utiliza o vocábulo aretê, o qual remete ao contexto de "o mais justo dos homens", a "excelência humana", ou seja, a clara percepção do reconhecidamente melhor. ${ }^{4}$ Contudo, Platão passou por três fases distintas no que tange seu entendimento acerca das Virtudes. A primeira fase está ligada à visão socrática, ou seja, o ponto inicial das

${ }^{2}$ GERVÁS, Manuel J. Rodríguez. Propaganda Política y Opinión Pública en los Panegíricos Latinos del Bajo Imperio. Salamanca: Universidad de Salamanca, 1991, p. 77.

${ }^{3}$ Estas obras tratam respectivamente sobre: temperança, fortaleza, estado ideal.

4 QUIRINO, C.L., VOUGA, C., BRANDÃO, G.M (org.). Clássicos do Pensamento Político. São Paulo: Edusp, 2004, p. 30. 
futuras discussões platônicas. Esta fase foi inspirada no princípio da razão, o qual necessariamente encaminharia para o conhecimento da alma. Conhecer a alma era preciso, visto que ela era o locus da Virtude e de seu oposto, o Vício. Esta primeira fase pode ser entendida com a seguinte passagem: "a alma é a essência do homem; sendo ela inteligência - ou seja RAZÃO -, então a Virtude é uma conseqüência desta inteligência, portanto a Virtude é conhecimento, e, se Virtude é conhecimento, ela se resume em uma só e única"5. Assim, entendemos que nesta primeira fase de Platão é o conhecimento que delimita todas as Virtudes.

A segunda fase de Platão já se distancia um pouco da visão socrática, principalmente com a escrita de A República. Neste momento, Platão ultrapassa a noção de que o todo da Virtude é o conhecimento/saber, admitindo que estas - as Virtudes - fazem parte de um todo, mas são distintas entre si. Isso ocorre principalmente, devido a sua tentativa de formar uma cidade ideal na obra $A$ República, onde seriam distribuídas várias funções aos indivíduos, os quais agiriam de acordo com determinadas Virtudes - coragem, temperança, sabedoria e justiça ${ }^{6}$. Todas as ações seriam voltadas ao próprio bem e ao bem de todos, com isso as Virtudes passam a ser entendidas como uma unidade necessária para harmonizar as diferenças. É nesta segunda fase que encontramos a definição platônica de que as Virtudes, tomadas em seu conjunto significariam a síntese que harmonizaria razão e paixão, e na qual ambas se transformariam para melhor. Tendo o domínio das Virtudes, o individuo alcançaria o estado da boa-aventurança.

A terceira e última fase de Platão que trata sobre as Virtudes se refere ao ensino destas. De forma clara e direta, o filósofo aponta para não possibilidade de se ensinar a Virtude, exceto se aparecer um sábio que consiga defini-la antes do ensinamento, o que para ele não

5 FEITOSA, Zoraida Maria Lopes. A Questão da Unidade e do Ensino das Virtudes em Platão. Tese (doutorado em História) - Faculdade de Filosofia, Letras e Ciências Humanas da Universidade de São Paulo (FFLCH/USP), 2006, p. 7.

${ }^{6}$ FEITOSA, Z.M.L. op.cit.,p. 9. 
existiu. Esta idéia é entendida se lembrarmos que a Virtude está ligada a alma do indivíduo, logo é pouco provável que se possa ensinar alguma coisa relacionada à alma humana ${ }^{7}$.

Com estes rápidos apontamentos, notamos o porquê que a palavra Virtude ficou carregada de subjetividades e abstrações. Contudo, existe a necessidade de localizar esta discussão no campo das virtudes que tratam sobre a essência de tal vocábulo. Estas, muito mais do que idealizar um individuo, tinham como função ajudar a atingir um estado elevado de bem-estar, a vida feliz. Este apontamento se faz necessário, pois notaremos que as Virtudes exaltadas em períodos posteriores, em especial no final do século I e inicio do séc. II d.C ganham outras funções e modos de uso. Contudo, ainda dispomos de outro autor que nos oferece recursos para entender esta gênese das Virtudes: o discípulo de Platão, Aristóteles.

Apesar de Aristóteles também conceber a idéia da ligação das Virtudes com o conhecimento/saber - "sem inteligência ninguém pode ser virtuoso, porque the faltaria o discernimento apropriado para deliberar e decidir corretamente em situações menos familiares"8 - ele apresenta uma nova idéia sobre a apropriação destas. Para seu mestre e, consequentemente para a doutrina socrática, as Virtudes pertencem ao intelecto do homem, tidas como inatas. Já para Aristóteles a Virtude se dava com a repetição de atos virtuosos, ou seja, era através da vontade do homem que se gerava o hábito virtuoso. É na obra Ética a Nicômaco que ele apresenta idéias sobre as Virtudes:

A virtude é, portanto uma disposição adquirida voluntariamente, que consiste, em relação a nós, na medida, definida pela razão em conformidade com a conduta de um homem ponderado. Ela ocupa a média entre duas extremidades lastimáveis, uma por excesso, a outra por falta. Digamos ainda o seguinte: enquanto, nas paixões e nas ações, o erro

\footnotetext{
${ }^{7}$ FEITOSA, Z.M.L. op.cit., p.11.

${ }^{8}$ MARQUES, Ramiro. O Livro das Virtudes de Sempre, Edição Asa, 2000.
} 
consiste ora em manter-se aquém, ora em ir além do que é conveniente, a virtude encontra e adota uma justa medida. Por isso, embora a virtude, segundo sua essência e segundo a razão que fixa sua natureza, consista numa média, em relação ao bem e à perfeição ela se situa no ponto mais elevado ${ }^{9}$.

Compreendemos que a Virtude aristotélica é o meio-termo entre o vício do excesso e o vício da falta ${ }^{10}$. Por exemplo:

Pode-se sentir tanto o medo, a confiança, o apetite, a cólera, a compaixão, e de uma forma geral o prazer e o sofrimento, em excesso ou em grau insuficiente; e em ambos os casos, isso é um mal. Mas senti-los no momento certo, em relação aos objetos e às pessoas certas, e pelo motivo e da maneira certa, nisso consistem o meio-termo e a excelência característicos da virtude ${ }^{11}$.

Entretanto um ponto muito interessante desta idéia sobre o "meio-termo" de Aristóteles, repousa na questão de que nem sempre se admite este meio-termo entre o excesso e a falta,

pois algumas entre elas têm nomes que já em si mesmos implicam maldade, como, por exemplo, o despeito, o despudor, a inveja, e, no âmbito das ações, o adultério, o roubo, o assassinato. Com efeito, nessas ações e paixões e outras semelhantes, a maldade não está na falta ou excesso, mas implícita nos próprios nomes. Nelas nunca será possível haver retidão, mas tão somente erro. E no que se refere a essas ações e paixões, tampouco a bondade ou a maldade dependem, por exemplo, do cometer adultério com a mulher certa, no momento e da maneira certos, mas simplesmente qualquer delas é um erro ${ }^{12}$.

Com estas idéias de Aristóteles chegamos ao fim do primeiro momento deste trabalho. O "retorno" às origens gregas da palavra Virtude, nos mostrou que seu uso encaminha-se para relações entre moral, ética e a incessante busca pela felicidade. Entretanto, esta

${ }^{9}$ ARISTÓTELES. Ética a Nicômaco. São Paulo: Martin Claret LTDA; trad. Pietro Nassetti., 2007, II, 6.

${ }^{10}$ LEVORIN, Paulo. A República dos Antigos e a República dos Modernos. Tese (doutorado em Ciência Política) - (FFLCH/USP), 2001, p. 22.

${ }^{11}$ ARISTÓTELES, op.cit., II, 6.

${ }^{12}$ ARISTÓTELES, op.cit. 
busca pela felicidade não exime os sofrimentos e os infortúnios que o homem virtuoso deve passar para alcançá-la. Este bem supremo está intimamente ligado à capacidade de atingir a felicidade, então lançamos uma última pergunta: Em que consiste esta felicidade? Aristóteles responde que tal felicidade seria atingida na medida em que o homem realizasse virtuosamente o que lhe é natural, ou seja, viver de acordo com o bom desenvolvimento do espírito racional, ser obediente, possuir e pensar sobre o elemento da razão.

Notamos que a discussão acerca das Virtudes no mundo grego alia-se a questão da natureza, da essência das Virtudes. Para este tipo de construção não há a necessidade da existência de um indivíduo em específico, o qual seja detentor destas Virtudes, mas sim que todos seguindo os preceitos indicados, poderiam tornar-se virtuosos. É através desta idéia que tentaremos estabelecer um paralelo com a concepção de Virtude encontrada no período inicial do principado romano.

A primeira questão que nos aparece é o uso da palavra Virtude acompanhada de Política - Virtude Política - e não a ênfase dada à Moral. Com isso notamos que a praticidade romana, em oposição à abstração grega, ganha corpo neste momento. Para melhor compreendermos este novo uso das Virtudes no período inicial do principado romano - aqui falo precisamente do final do século I e inicio do século II d.C - cito um pequeno trecho do artigo Propaganda Política y Opinión Publica en los Panegíricos Latinos del Bajo Imperio de Manuel Rodriguéz Guervás: "Las 'virtudes' tenían pués, la función de elaborar, formalizar e intensificar la imagen imperial con el objetivo básico de crear uma estructura política unitaria"13, são idéias que apontam para o uso Político das Virtudes, com objetivos bem definidos e com o mínimo de abstração possível.

${ }^{13}$ AXTELL, H. L. apud: GUERVÁS, Manuel J. Rodríguez. Propaganda Política y Opinión Pública en los Panegíricos Latinos del Bajo Imperio. Salamanca: Universidad de Salamanca, 1991, p.77. 
É esta preocupação em "exaltar um individuo" específico, que entendemos como a grande diferença entre as Virtudes gregas e as romanas. Cabe aqui uma breve explicação: não há uma mudança significativa do conteúdo filosófico das Virtudes gregas para as romanas, mas sim da forma em que elas foram usadas. Continua-se a idéia da moralidade, mas atrela-se a ela um modelo individual a ser seguido, ou seja, a necessidade da personificação destas Virtudes para que um individuo as ostente.

Com este principio da ostentação virtuosa, chegamos a outra característica das Virtudes Políticas Romanas. A autora Maria José Hidalgo de la Vega com o texto El Intelectual, La Realeza y el Poder Político en el Império Romano aponta para um caminho complementar ao da ostentação - chamado pela autora de "glorificação individual". Ao mesmo tempo em que as Virtudes glorificam/ostentam/idealizam, elas podem contrapor este individuo a outro que deve ser diminuído. Para estas idéias ganharem corpo, trago rapidamente um caso: Plínio, o Jovem ${ }^{14}$ ao escrever seu

${ }^{14}$ Caio Plínio Cecílio Segundo, nascido por volta de 61 d.C pertenceu a uma família abastada, a qual lhe proporcionou ótimos estudos. Ganhou o epíteto de Plínio, o Jovem por ser sobrinho e filho adotivo de Plínio, o Velho, tendo este último morrido na explosão do Vesúvio e tal incidente foi relatado por Plínio, o Jovem. Seus estudos começaram na linha da retórica e das leis, tendo Quintiliano e Nicetas de Esmirna como orientadores. Não tardou para iniciar sua carreira de advogado - dezoito anos - e em pouco tempo conseguiu uma rápida ascensão no cursus honorum; começando como Questor no reinado de Domiciano (91 d.C) cuidava do tesouro público - passando no ano seguinte a Tribuno da Plebe e em 95 d.C a Pretor - administrador da justiça. No período de Nerva (97 d.C) aproximouse do imperador, o que lhe deu facilidades de contato com o futuro imperador Trajano, visto que Nerva morreu em menos de um ano de governo. No período de Trajano, Plínio, o Jovem conseguiu o cargo de Tesoureiro de Saturno, tendo chego a cônsul no ano 100 d.C. Plínio revelou-se um intelectual porta-voz senatorial, que seguindo os ensinamentos de seu mestre Quintiliano, deveria se adaptar às necessidades do momento para ocupar postos de prestígio na administração do Estado. Dessa forma, aceitou prontamente o cargo de Governador da Província da Bitinia, tendo exercido tal função de 111 a 113 d.C. 
Epistolário e o Panegírico a Trajano ${ }^{15}-98$ a 113 d.C - atendeu a estes pressupostos do uso das Virtudes. Exaltou a figura do Imperador dando a este várias qualidades, equiparando-o ao modelo mais perfeito até aquele momento, Augusto. Ao construir esta imagem idealizada de Trajano, acabou por diminuir e denegrir o antecessor, Domiciano, considerado por Plínio, o Jovem um déspota. Interessante apontar que a forma a qual Plínio, o Jovem utilizou das Virtudes não teve como função usar a atividade racional para chegar até o bem supremo, mas sim personificá-las em um individuo ideal. Podemos notar esta relação das Virtudes com um "utilitarismo" na Carta LI de Plínio:

É difícil, domine, achar palavras para exprimir quão feliz você me deixou, com sua bondade para comigo e minha sogra, em transferir seu parente Caelius Clemens a esta província ${ }^{16}$. Começo a entender plenamente a extensão de sua generosidade quando ela é graciosamente estendida a toda minha família: eu não posso me arriscar a pagar por isto, por mais que minha capacidade talvez consiga. Eu só posso aceitar seu favor e rogar aos deuses para que eu nunca possa ser indigno dos favores que você continuamente outorga ${ }^{17}$.

${ }^{15}$ Marco Ulpio Trajano, diferente dos imperadores que o antecederam, não possuía origem classicamente romana. Considerado como o primeiro imperador de origem provinciana, foi adotado pelo imperador Nerva, principalmente, pelo seu forte caráter militar. Nasceu em 18 de setembro de 53 d.C, tendo ascendência eqüestre sendo este um dos possíveis motivos de sua inclinação às questões militares, e tendo em sua própria família um norteador, seu pai Mário Ulpio Trajano, militar de destaque no período de Vespasiano (69 d.C-79 d.C). Foi no principado de Trajano que as campanhas contra os Dácios - 101 a 102 d.C e 105 a 107 d.C - e contra os inimigos tradicionais dos romanos, os Partos - 117 d.C - foram levadas a cabo. Apesar destes grandes marcos - as campanhas militares - Trajano também se dedicou a algumas obras de saneamento, principalmente a reforma de banhos públicos em províncias romanas; construções de teatros; de tubulações; problemas relacionados ao trato de escravos e, uma tenra preocupação com a nova superstitionem chamada de cristianismo.

${ }^{16}$ Clemens, um parente de Celerina de Pompéia, provavelmente veio como um tribuno militar.

${ }^{17}$ Pliny Letters, Book X, Panegyricus. London: Harvard University Press; trad. Betty Radice. 
Notamos que tanto a bondade quanto a generosidade estão ligadas a favores/ações do Imperador em relação a Plínio, o Jovem. Estas qualidades estão ligadas a virtude, no latim, indulgentiae a qual ficou claramente ligada com estes gestos de boas-ações. Plínio não buscou a essência desta virtude, suas implicações morais, etc., mas sim o seu uso direto e prático - estender os favores para outros indivíduos. Poderíamos nos inquietar com uma possível ligação entre o hábito virtuoso de Aristóteles e a passagem em que Plínio fala "(...) para que eu nunca possa ser indigno dos favores que você continuamente outorga", entretanto notamos a praticidade de tal "continuamente outorga", visto que está ligado com os favores e não com a essência virtuosa.

De um bem supremo, quase que inatingível, passamos para algo tocável, ou melhor, passível de definição. Moderação, Concórdia, Clemência, Fidelidade são Virtudes carregadas de princípios morais - confiança, justiça, bondade, afeto - entretanto, passam a ser exaltadas uma a uma, sem a necessidade de entender sua natureza, mas sim sua real aplicação. O que nos leva a uma real busca por um exemplo carnal.

\section{BIBLIOGRAFIA}

ARISTÓTELES. Ética a Nicômaco. São Paulo: Martin Claret LTDA; Trad. Pietro Nassetti, 2007.

FEITOSA, Zoraida Maria Lopes. A Questão da Unidade e do Ensino das Virtudes em Platão. Tese (doutorado em História) - Faculdade de Filosofia, Letras e Ciências Humanas da Universidade de São Paulo (FFLCH/USP), 2006.

GERVÁS, Manuel J. Rodríguez. Propaganda Política y Opinión Pública en los Panegíricos Latinos del Bajo Imperio. Salamanca: Universidad de Salamanca, 1991. 
LEVORIN, Paulo. A República dos Antigos e a República dos Modernos. Tese (doutorado em Ciência Política) - (FFLCH/USP), 2001.

MARQUES, Ramiro. O Livro das Virtudes de Sempre. Edição Asa, 2000.

PARATORE, Etorre. A História da Literatura Latina. Firenze: Sansoni Editore, 1983.

PEREIRA, Maria Helena da Rocha. Idéias Morais e Políticas dos Romanos. In: Estudos de História da Cultura Clássica. Lisboa: Fundação Calouste Gulbenkian.

QUIRINO, C.L., VOUGA, C., BRANDÃO, G.M (Org.). Clássicos do Pensamento Político. São Paulo: Edusp, 2004.

VEGA, María José Hidalgo de La. El Intelectual, la Realeza y el Poder Político en el Imperio Romano. Salamanca: Ediciones Universidad de Salamanca, 1995.

VENTURINI, Renata Lopes Biazotto. As Palavras e as Idéias: o Poder na Antiguidade. Diálogos, DHI/PPH/UEM, v. 9, n. 2, p. 142$155,2005$. 